\title{
Regulating the Skin Permeation Rate of Escitalopram by Ion-pair Formation with Organic Acids
}

\author{
Tian Song, ${ }^{1}$ Peng Quan, ${ }^{1}$ Rongwu Xiang, ${ }^{1}$ and Liang Fang ${ }^{1,2}$
}

Received 22 September 2015; accepted 22 December 2015; published online 13 January 2016

\begin{abstract}
In order to regulate the skin permeation rate (flux) of escitalopram (ESP), ion-pair strategy was used in our work. Five organic acids with different physicochemical properties, benzoic acid (BA), ibuprofen (IB), salicylic acid (SA), benzenesulfonic acid (BSA), and $p$-aminobenzoic acid (PABA), were employed as counter-ions to regulate the permeation rate of ESP across the rabbit abdominal skin in vitro. The interaction between ESP and organic acids was characterized by FTIR and ${ }^{13} \mathrm{C}$ NMR spectroscopy. Results showed that all organic acids investigated in this study performed a controlling effect on ESP flux. To further analyze the factors concerned with the permeation capability of ESP-acid complex, a multiple linear regression model was used. It is concluded that the steady-state flux $(J)$ of ESP-acid complexes had a positive correlation with $\log K_{\mathrm{o} / \mathrm{w}}$ (the $n$-octanol/water partition coefficient of ion-pair complex) and $\mathrm{p} K_{\mathrm{a}}$ (the acidity of organic acid counter-ion), but a negative correlation with $M W$ (the molecular weight of ionpair complex). The $\log K_{\mathrm{o} / \mathrm{w}}$ of ion-pair complex is the primary one in all the factors that influence the skin permeation rate of ESP. The results demonstrated that organic acid with appropriate physicochemical properties can be considered as suitable candidate for the transdermal drug delivery of escitalopram.
\end{abstract}

KEY WORDS: escitalopram; ion-pair; multiple line regression; transdermal drug delivery; ${ }^{13} \mathrm{C}$ NMR.

\section{INTRODUCTION}

Depression is one of the most common psychiatric disorders worldwide (1). It is predicted that by 2030 depression will become the foremost contributor to the worldwide burden of disease (2). At present, oral administration is the main route to treat depression and patients are required to keep taking medicine everyday for a very long time, which greatly increases the mental burden of patients. Escitalopram (ESP, Fig. 1a), the $S(+)$ enantiomer of citalopram, is one of the most effective selective serotonin reuptake inhibitors (SSRIs) and is known to be effective in the treatment of depression (3). In 2002, the escitalopram oxalic acid tablet was approved by FDA for marketing and the daily oral dose was $10-20 \mathrm{mg}$. After oral administration, the most common gastrointestinal side effects are nausea and xerostomia. ESP will increase the serotonin levels both in the brain and in the gastrointestinal tract. The former shows benefits in relieving depression, while the latter causes some gastrointestinal side effects like anorexia, nausea, and vomiting. In particular, elderly patients have an increased risk of gastrointestinal bleeding when taking SSRIs $(4,5)$.

Transdermal drug delivery system (TDDS) is an ideal alternative for ESP to bypass the gastrointestinal side effects from oral administration. Moreover, escitalopram has a low

\footnotetext{
${ }^{1}$ Department of Pharmaceutics, Shenyang Pharmaceutical University, 103 Wenhua Road, Shenyang, 110016, People's Republic of China.

${ }^{2}$ To whom correspondence should be addressed. (e-mail: fangliang2003@yahoo.com)
}

molecular weight and the daily dose needed is small, which makes it a promising candidate for transdermal delivery. As we all know, transdermal delivery provides controlled and constant administration of drugs, which has smoothed plasma drug concentration versus time curve, thus, decreasing the side effects and increasing the tolerability. But if the skin permeation rate (flux) is too high, sustained-release effect of drug is unattainable, and the peak of drug concentration in plasma will also appear. In addition, our preliminary work showed the flux of ESP from the vehicle of isopropyl palmitate (IPP) in $8 \mathrm{~h}$ was $224.48 \pm 18.49 \mu \mathrm{g} /\left(\mathrm{cm}^{2} \mathrm{~h}\right)$, which was too high to maintain a slow and sustained the absorption of drug through the skin. Our goal is to prepare a long-acting ESP transdermal patch, which can provide a curative effect for 3 to 7 days. It is easy to decrease the flux of ESP by directly reducing its content, which in turn brings about the problem of dose depletion for long-acting transdermal patches. Thus, we cannot reduce the dose delivered or use a smaller patch (6). The flux of ESP should be controlled and the cumulative penetration amounts should meet the requirement of the long-acting ESP transdermal patch.

Ion-pair is a simple method that gains success in enhancing skin permeation of many drugs (7). For example, Sarveiya et al. showed that lipophilic counter-ions ibuprofen and benzoic acid increased in vitro permeation of benzydamine across polydimethylsiloxane membrane (8). Similarly, the ion-pair strategy also can be used to change the physicochemical properties of ESP to control the drug skin permeation rate in a moderate range. In our lab, ion-pair strategy has been used to control the skin permeating the rate of bisoprolol for 
a

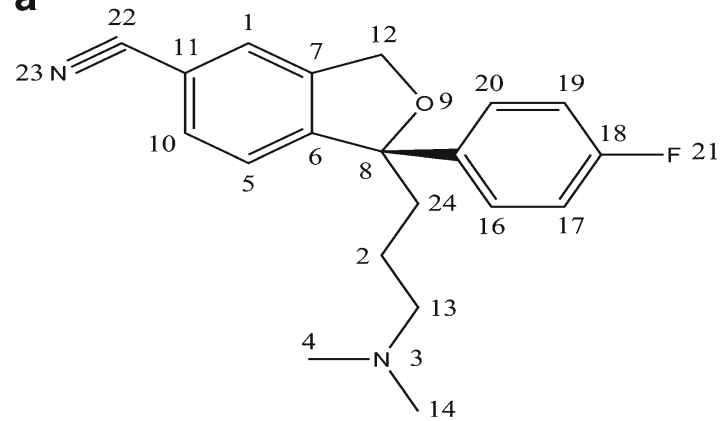

C

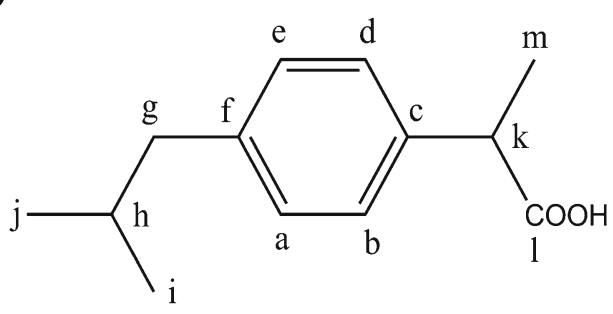

e<smiles>Nc1ccc(C(=O)O)cc1</smiles>

b<smiles>O=C(O)c1ccccc1</smiles>

d<smiles>O=C(O)c1ccccc1O</smiles>

f<smiles>O=S(=O)(O)c1ccccc1</smiles>

Fig. 1. Chemical structures of a ESP, b BA, c IB, d SA, e PABA, f BSA

long-acting transdermal patch (9). Therefore, ESP, a weak base ( $\left.\mathrm{p} K_{\mathrm{a}}=9.57\right)$, may be combined with counter-ions of organic acids to regulate the flux to obtain an effective transdermal patch. In order to explore the effect of organic acid on the skin permeation rate of ESP, five different organic acids, including benzoic acid (BA), ibuprofen (IB), salicylic acid (SA), benzenesulfonic acid (BSA), and $p$-aminobenzoic acid (PABA), were employed as counter-ions (Fig. 1). Multiple linear regression analysis was used to investigate the relationship between the flux of ESP and the physicochemical properties of ion-pairs. FTIR and ${ }^{13} \mathrm{C}$ NMR spectroscopy were used to characterize the ion-pair formation.

\section{MATERIALS AND METHODS}

\section{Materials}

Escitalopram oxalate was purchased from Eastbang Pharmaceutical Co., Ltd. (Guangdong, China). Benzoic acid, salicylic acid, benzene sulfonic acid, and $p$-aminobenzoic acid were obtained from Tianjin Bodi Chemical holding Co., Ltd. (Tianjin, China). Ibuprofen was purchased from Baikehengdi Pharmaceutical Co., Ltd. (Hubei, China). Acetone and IPP were obtained from Shanghai Qianwei Oil Science \& technology Co., Ltd. (Shanghai, China). Triethylamine, acetic acid, ethylparaben, sodium hydroxide, HPLC grade methanol, and ethyl acetate were purchased from the Yuwang Pharmaceutical Co., Ltd. (Shandong, China). Deuterium generation of chloroform $\left(\mathrm{CDCl}_{3}\right)$ was obtained from Cambridge Isotope Laboratories (America). All other chemicals and solvents were of the highest reagent grade available.

The free escitalopram was extracted by ethyl acetate from escitalopram oxalate (ESP-OA) solution which was adjusted to $\mathrm{pH} 11$ by sodium hydroxide $(4 \%, w / v)(10)$. It was identified by differential scanning calorimetry (DSC) and Fourier transform infrared (FTIR).

Acetone was used as a solvent for preparing ion-pair complexes. The mixing solutions with free escitalopram and equimolar amounts of organic acids were stirred for approximately $2 \mathrm{~h}$, then concentrated under vacuum, and the ESPacid complexes were obtained and identified by DSC and ${ }^{13} \mathrm{C}$ NMR.

\section{In Vitro Permeation Experiments}

Rabbits (male, 1.5-2.0 kg) were obtained from the Experimental Animal Center of Shenyang Pharmaceutical University (Shenyang, China). The experimental protocol was evaluated and approved by the University Ethics Committee for the use of experimental animals and conformed to the Guide for Care and Use of Laboratory Animals. Skin preparation was performed in accordance with a process reported earlier (11).

In vitro permeation experiments were performed at $32^{\circ} \mathrm{C}$ in a two-chamber side-by-side glass diffusion cell. Each cell 
has a volume of $4.0 \mathrm{~mL}$ and an effective diffusion area of $0.95 \mathrm{~cm}^{2}$. The cells were connected to a water bath circulator at $32^{\circ} \mathrm{C}$. The excised rabbit skin was mounted between the cell halves with the dermal side faced the receiver solution. The suspensions of ESP or ESP ion-pair complexes in IPP were applied in the donor compartment, and the phosphate buffered saline (PBS, pH 7.4) was added into the receptor com-

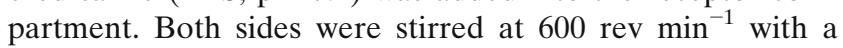
magnetic bar driven by a synchronous motor. Two milliliters of receptor solution was withdrawn at every predetermined sampling times $(1,2,3,4,5,6,7$, and $8 \mathrm{~h})$, and the same volume of fresh receptor medium was added to the receiver compartment to maintain sink conditions. The samples were analyzed by HPLC after the centrifugation and appropriate dilution. The cumulative amount of drug permeated per unit area $(Q)$ versus time was plotted. The slope of the linear portion of the plot was calculated as the steady-state flux $(J$, $\left.\mu \mathrm{g} /\left(\mathrm{cm}^{2} \mathrm{~h}\right)\right)$.

\section{Determination of Apparent Solubility}

The solubility of ESP and its complexes in IPP solutions were determined at $32^{\circ} \mathrm{C}$, by adding excessive drugs to the vehicle in glass vials. All vials were shaken for $48 \mathrm{~h}$ until equilibrium. After filtering and dilution, the concentration of each drug was determined by HPLC.

\section{Determination of Apparent Partition Coefficient}

The apparent partition coefficient $\left(\log K_{\mathrm{o} / \mathrm{w}}\right)$ was determined by classic shake-flask method. ESP or ion-pairs complexes were added into $n$-octanol saturated with water and mixed with equal volume water saturated with $n$-octanol in glass vials. The samples were shaken for $48 \mathrm{~h}$ at $32^{\circ} \mathrm{C}$. After filtering and proper dilution, the drug concentrations in both water layer and $n$-octanol layer were analyzed by HPLC.

a

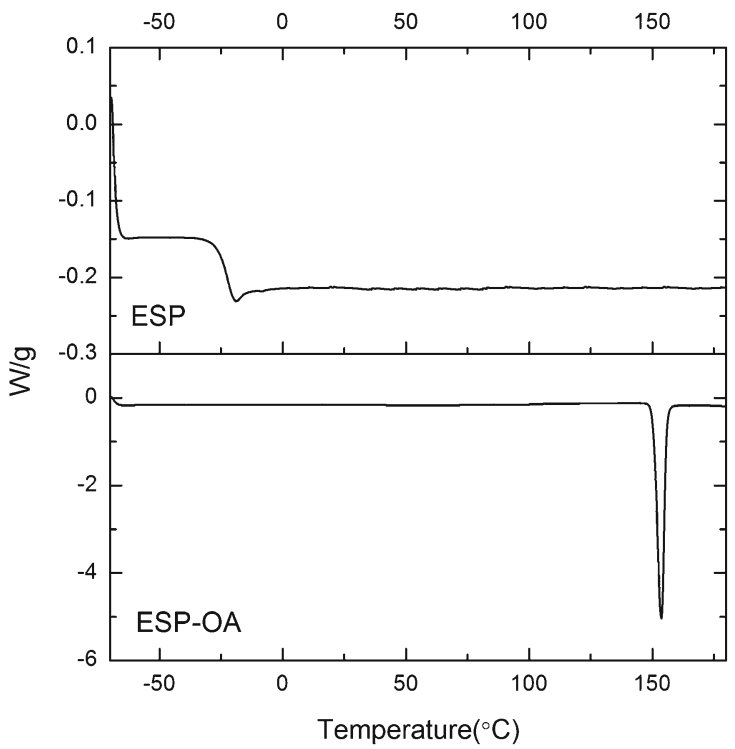

\section{HPLC Analysis}

Quantitative determination of the ESP and complexes was performed using a HPLC system consisting of an L-2420 ultraviolet absorbance detector and an L-2130 pump (Hitachi High-Technologies Corporation, Tokyo, Japan). The HPLC column $(200 \mathrm{~mm} \times 4.6 \mathrm{~mm} \times 5 \mu \mathrm{m})$ was Diamonsil C18 (Dikma Technologies, Beijing, China). The mobile phase consisted of methanol and $0.5 \%$ triethylamine in distilled water $(55: 45$, $v / v)$, and the $\mathrm{pH}$ was adjusted to 3.0 with phosphoric acid. The flow rate was $1 \mathrm{~mL} / \mathrm{min}$ and the detection wavelength was $238 \mathrm{~nm}$. Retention times for ESP, BA, IB, SA, PABA, and BSA were 4.5, 6.5, 6.0, 7.5, 3, and $3.6 \mathrm{~min}$, respectively.

\section{Statistical Analysis}

All experiments were replicated three or four times, and the data were calculated and presented as mean \pm SD. Statistical analyses of the data were performed using analysis of variance and the Student's $t$ test. The level of significance was taken as $P<0.05$.

\section{RESULTS}

\section{Characterization of Free ESP}

DSC was utilized to measure the melting point of ESPOA and free ESP. As shown in (Fig. 2a), a sharp endothermic peak at $153.67^{\circ} \mathrm{C}$ was observed owing to the melting of ESPOA, while the melting point of free ESP occurred at $-19.33^{\circ} \mathrm{C}$, which indicated that the free ESP might be prepared.

The free ESP was also characterized by FTIR. In Fig. 2b, the peak at $2230 \mathrm{~cm}^{-1}$ of ESP and ESP-OA was assigned to the stretching vibration of $-\mathrm{C} \equiv \mathrm{N}$. The peak at $2705 \mathrm{~cm}^{-1}$ in spectra of ESP-OA was due to the stretching vibration of tertiary amine salt $\mathrm{H}-\mathrm{N}^{+}(12)$. However, the similar signal was not found in the spectra of ESP. Furthermore, the ESP-OA showed a carbonyl stretching vibration peak around

b

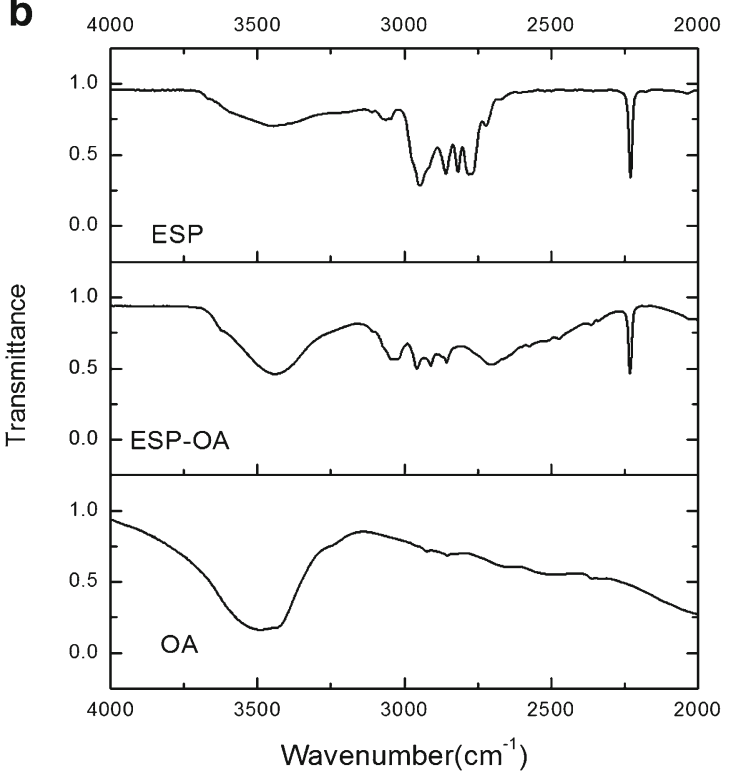

Fig. 2. The DSC thermograms of free ESP and ESP-OA complex (a) and FTIR spectra of free ESP, OA, and ESP-OA complex (b) 
Table I. ${ }^{13} \mathrm{C}$ NMR chemical shifts $(\delta$, ppm) of $\mathrm{C} 2, \mathrm{C} 4$, and $\mathrm{C} 13$ of ESP, and shift changes $(\Delta \delta$, ppm) in the presence of organic acids

\begin{tabular}{lcccccc}
\hline ESP & ESP $\delta$ & ESP-BA $\Delta \delta$ & ESP-IB $\Delta \delta$ & ESP-SA $\Delta \delta$ & ESP-PABA $\Delta \delta$ & ESP-BSA $\Delta \delta$ \\
\hline C2 & 22.131 & -1.981 & -2.134 & -2.351 & -1.441 & -2.451 \\
C4 & 45.318 & -2.358 & -1.278 & -2.628 & -1.798 & -2.038 \\
C13 & 59.407 & -1.777 & -1.938 & -1.827 & -1.357 & -1.397 \\
\hline
\end{tabular}

$\Delta \delta=\delta_{\mathrm{ESP}-\mathrm{acid}^{-}} \delta_{\mathrm{ESP}}$

$1700 \mathrm{~cm}^{-1}$, which was disappeared in the spectra of ESP, indicating the preparation of free ESP. The optical rotations of ESP-OA and ESP were measured in a 1-dm cell of $10-\mathrm{mL}$ capacity using a WXG-4 Disc Polarimeter (Shanghai, China). The optical rotation of ESP $\left([\alpha]_{\mathrm{D}}{ }^{25}=+9.25(\mathrm{C}=0.01 \mathrm{~g} / \mathrm{mL}\right.$, methanol)) is similar with ESP-BA $\left([\alpha]_{\mathrm{D}}{ }^{25}=+8.45\right.$ $(\mathrm{C}=0.01 \mathrm{~g} / \mathrm{mL}$, methanol $)$ ).

\section{Characterization of ESP Ion-pair Complexes}

\section{${ }^{13}$ C NMR Spectroscopy}

${ }^{1} \mathrm{H}$ and ${ }^{13} \mathrm{C}$ NMR spectroscopy can be used to study the phenomenon of charge transfer happening in the process of complexes formation, but Sarveiya et al. demonstrated that the carbon atoms had a greater sensitivity to the electronic effects than proton atoms (8). Therefore, ${ }^{13} \mathrm{C}$ NMR spectroscopy was used to obtain the evidence of ion-pair formation between ESP and different organic acids. In comparison of the carbon NMR spectra of ESP and ESP-acids, the largest chemical shift changes were observed in methylene (C13 and C2) and the methyl carbons (C4) attached to nitrogen, which showed upfield shifts from -1.278 to $-2.628 \mathrm{ppm}$ (Table I). This chemical shift change was just opposite to the other typical complex formation systems wherein hydrogen bond formation was clearly observed by NMR spectroscopy (13). In our studies, due to the steric hindrance, these carbons neighboring nitrogen were considered in the shielding zone of the aromatic ring when interacted with organic acid and so that appeared upfield shift changes (14). Furthermore, Table II also showed large chemical shift changes in carboxyl group in the presence of ESP such as C (1) in ibuprofen $(-1.508 \mathrm{ppm})$ and $\mathrm{C}(\mathrm{g})$ in benzoic acid $(-0.76 \mathrm{ppm})$. This value indicated that the charge on the carboxyl group had been partially neutralized. Besides, a downfield shift change was observed in the aromatic ring of organic acids like $\mathrm{C}$ (c) in ibuprofen (1.884 ppm), C (f) in benzoic acid (2.04 ppm), and C (b) in salicylic acid (1.6 ppm). The structure of ESP may enhance the conjugation effect between aromatic ring and carbonyl group, the adjacent carbons in aromatic ring showed downfield change. Similarly, in the NMR spectra of ESP-BSA complex, change was also observed (1.48 ppm) in $C$ (f). In summary, the chemical shift changes of carbons provided an evidence of ion-pair formation between ESP and organic acids.

\section{FTIR Spectroscopy}

FTIR spectroscopy proved the interaction between ESP and the counter-ions existed. All the spectra of organic acids and ESP ion-pair complexes were depicted in Fig. 3. Peaks around $1720-1650 \mathrm{~cm}^{-1}$ were caused by the stretching vibration of carboxyl groups of different organic acids. However, due to the interaction with ESP, the peak got red shifted to a low wavenumber, and an asymmetric carboxylate stretching band was seen at $1540-1610 \mathrm{~cm}^{-1}$ in the spectra of ion-pair complexes (15). Similarly, the characteristic peaks of sulfonic group at $1100-1200 \mathrm{~cm}^{-1}$ also shifted to a low wavenumber after the formation of ESP-BSA complex.

\section{Effect of Organic Acids on the Permeation of ESP}

The flux value of ion-pair complexes and their physicochemical properties was summarized in Table III. It can be seen that free ESP had the highest flux $(J=224.48 \pm 18.49 \mu \mathrm{g} /$ $\left.\left(\mathrm{cm}^{2} \mathrm{~h}\right)\right)$, while ESP ion-pair complexes had different flux value ranging from 0.32 to $169.85 \mu \mathrm{g} /\left(\mathrm{cm}^{2} \mathrm{~h}\right)$. The wide deviations demonstrated that the permeability of escitalopram was significantly influenced by the organic acids with different physicochemical properties. The permeation profiles were presented in Fig. 4.

To estimate the quantitative effects of the physicochemical properties on the skin permeation rate of escitalopram, a multiple linear regression model was carried out to detect the correlation between $\ln J$ (converting from the flux value $(J)$ ) and the $M W, \log K_{\mathrm{o} / \mathrm{w}}$ of ion-pair complexes, the $\mathrm{p} K_{\mathrm{a}}$ of organic acid. The regression equation was expressed as follows:

$\ln J=24.549+3.154 * \log K_{\mathrm{o} / \mathrm{w}}-0.051 * M W+0.575 * p K_{\mathrm{a}}$

Table II. ${ }^{13} \mathrm{C}$ NMR shift changes $(\Delta \delta$, ppm) in organic acids in the presence of ESP

\begin{tabular}{|c|c|c|c|c|c|c|c|c|c|}
\hline $\mathrm{BA}$ & & IB & & SA & & $\mathrm{PABA}^{a}$ & & $\mathrm{BSA}^{b}$ & \\
\hline $\mathrm{b}$ & 0.52 & $\mathrm{c}$ & 1.884 & $\mathrm{~b}$ & 1.6 & $\mathrm{f}$ & 1.11 & $\mathrm{~b}$ & 0.62 \\
\hline $\mathrm{f}$ & 2.04 & $\mathrm{k}$ & -2.207 & $\mathrm{f}$ & 0.68 & $\mathrm{~g}$ & -1.06 & $\mathrm{f}$ & 1.48 \\
\hline $\mathrm{g}$ & -0.76 & 1 & -1.508 & $\mathrm{~g}$ & -0.84 & & & & \\
\hline
\end{tabular}

$\Delta \delta=\delta_{\text {ESP-acid }}-\delta_{\text {acid }}$

${ }^{a}$ The chemical shifts of PABA were obtained from SciFinder database

${ }^{b}$ The chemical shifts of BSA were obtained from Eikema et al. (27) 


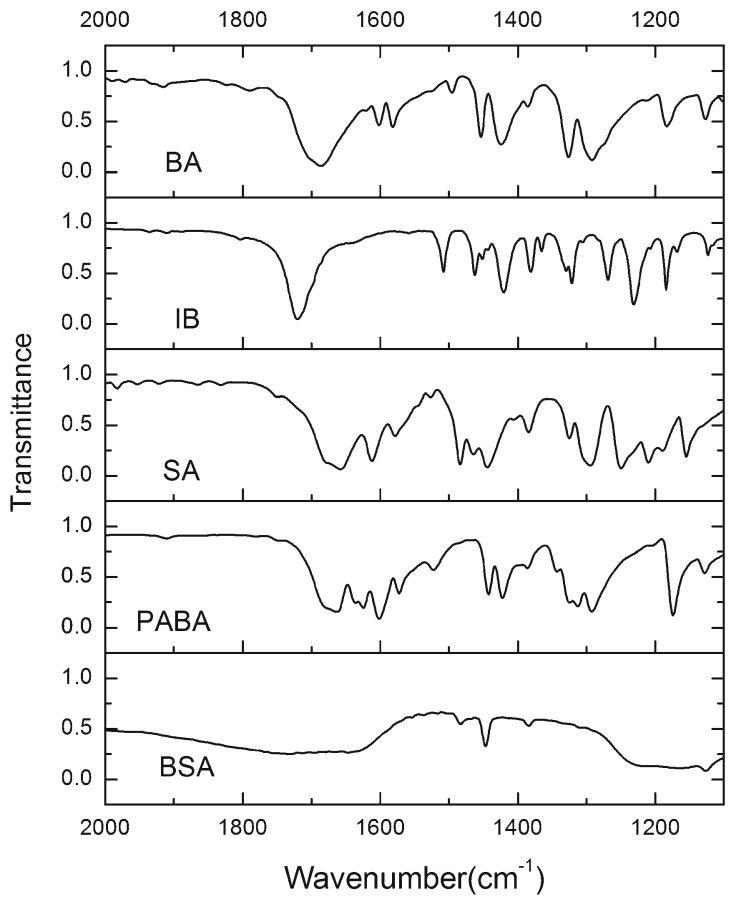

Fig. 3. The FTIR spectra of free ESP and its ion-pair complexes

The adjusted $R^{2}$ value was 0.999 and $P=0.018<0.05$, which indicated the model was suitable for describing the relationship between the independent variables and the response. Table IV showed the significance test results of each variable coefficient of the model equation. It can be seen that all the coefficients significantly contribute to the model $(P<0.05)$. Based on the multiple linear regression equation, response variable $\ln J$ had a positive correlation with $\log K_{\mathrm{o} / \mathrm{w}}$ and $\mathrm{p} K_{\mathrm{a}}$, but a negative correlation with $M W$. The response surface of $\ln J$ (Fig. 5) was obtained according to the multiple linear regression model equation. The typical plane model indicates that the flux value of ion-pair complexes and their physicochemical properties show a good linear relation. Besides, the standardized coefficients listed in Table IV conveyed the intensity of effect of the independent variables. By analysis of $M W, \mathrm{p} K_{\mathrm{a}}$, and $\log K_{\mathrm{o} / \mathrm{w}}$ of ESP-acids, the $\log K_{\mathrm{o} / \mathrm{w}}$ showed the greatest effect on the skin permeation rate of ESP.

\section{DISCUSSION}

According to proton-transfer model of Huyskens and Zeegers-Huyskens (16), the formation of ion-pairs could be achieved when the $\Delta \mathrm{p} K_{\mathrm{a}}$ between acids and amines was in a

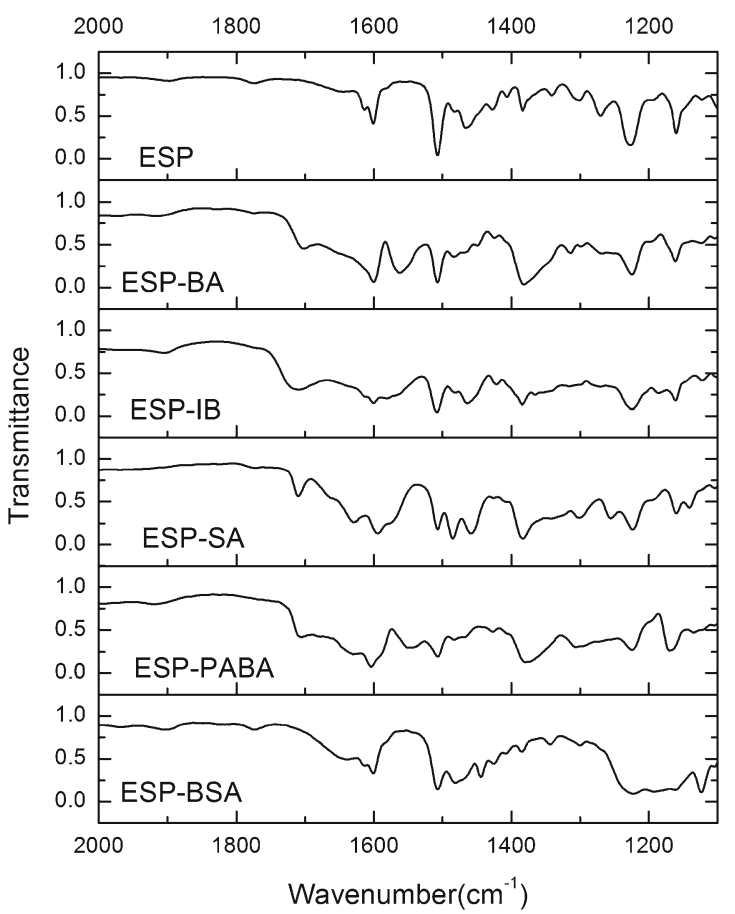

particular domain $\left(2.46<\Delta \mathrm{p} K_{\mathrm{a}}<6, \Delta \mathrm{p} K_{\mathrm{a}}=\mathrm{p} K_{\mathrm{a} \text {, amine }}-\mathrm{p} K_{\mathrm{a}, \text { acid }}\right)$. Therefore, it was possible to form ion-pairs between the tertiary amine of ESP $\left(\mathrm{p} K_{\mathrm{a}}=9.57\right)$ and the carboxylic acids of five counter-ions in $\mathrm{O}-\mathrm{H}^{\cdots} \mathrm{N} \leftrightarrow \mathrm{O}^{-\cdots} \mathrm{H}-\mathrm{N}^{+}$system. According to Bjerrum's equation (17), a solvent with a low dielectric constant $(\varepsilon)$ was favorable for the ion-pair formation and interactions between opposite ions become increasingly important in solvents with $\varepsilon<40$. In this study, acetone was used to prepare ESP ion-pairs not just because of its low dielectric constant $(\varepsilon=19.5)$ but also its good dissolving capacity to ESP and all other counter-ions. As the dielectric constant of $\mathrm{CDCl}_{3}$ was 4.81, it was favorable to form ion-pair complex and applied as the solvent in ${ }^{13} \mathrm{C}$ NMR spectroscopy study. However, the BSA and PABA had a low solubility in $\mathrm{CDCl}_{3}$ so we did not obtain the ${ }^{13} \mathrm{C}$ NMR spectra of BSA and PABA. IPP is a lipophilic solvent with low dielectric constant $(\varepsilon=3.18)$, which is frequently used in the study of transdermal drug delivery. The permeation experiment from IPP ignored the complicated influence of patch matrix, thus, the flux from IPP can be regarded as an indicator of drug skin permeability (18).

It is generally accepted that a drug permeates through the skin by way of lipophilic stratum corneum (SC) and aqueous viable epidermis (ED). Drugs like ESP with proper $\log K_{\mathrm{o} / \mathrm{w}}$

Table III. The permeation data and physicochemical parameters for ESP with or without various organic acids (mean $\pm \mathrm{SD}, n=4)$

\begin{tabular}{lccccrr}
\hline Permeants & $Q_{8 \mathrm{~h}}\left(\mu \mathrm{g} / \mathrm{cm}^{2}\right)$ & $J\left(\mu \mathrm{g} /\left(\mathrm{cm}^{2} \mathrm{~h}\right)\right)$ & $\log K_{\mathrm{o} / \mathrm{w}}$ & $M W$ & $\mathrm{p} K_{\mathrm{a}}{ }^{a}$ & $S^{b}(\mathrm{ug} / \mathrm{ml})$ \\
\hline ESP & $1647.84 \pm 170.03$ & $224.48 \pm 18.49$ & $0.79 \pm 0.06$ & 324.39 & 9.57 & $47957.53 \pm 778.24$ \\
ESP-BA & $1235.99 \pm 207.13$ & $169.85 \pm 27.97$ & $0.31 \pm 0.03$ & 446.51 & 4.20 & $3771.56 \pm 215.46$ \\
ESP-IB & $995.13 \pm 144.19$ & $113.09 \pm 20.65$ & $1.52 \pm 0.08$ & 530.67 & 4.41 & $18072.93 \pm 513.49$ \\
ESP-SA & $381.69 \pm 76.74$ & $45.61 \pm 9.17$ & $0.4 \pm 0.02$ & 462.51 & 3.01 & $995.01 \pm 67.74$ \\
ESP-PABA & $307.36 \pm 36.09$ & $35.11 \pm 4.95$ & $-0.05 \pm 0.05$ & 461.52 & 4.86 & $1188.49 \pm 103.99$ \\
ESP-BSA & $2.27 \pm 0.19$ & $0.32 \pm 0.04$ & $-0.21 \pm 0.06$ & 482.57 & -0.60 & $79.09 \pm 14.00$ \\
\hline
\end{tabular}

${ }^{a} \mathrm{p} K_{\mathrm{a}}$ of organic acid counter-ion. The dates were obtained from SciFinder database

${ }^{b}$ Solubility in isopropyl palmitate (IPP) 


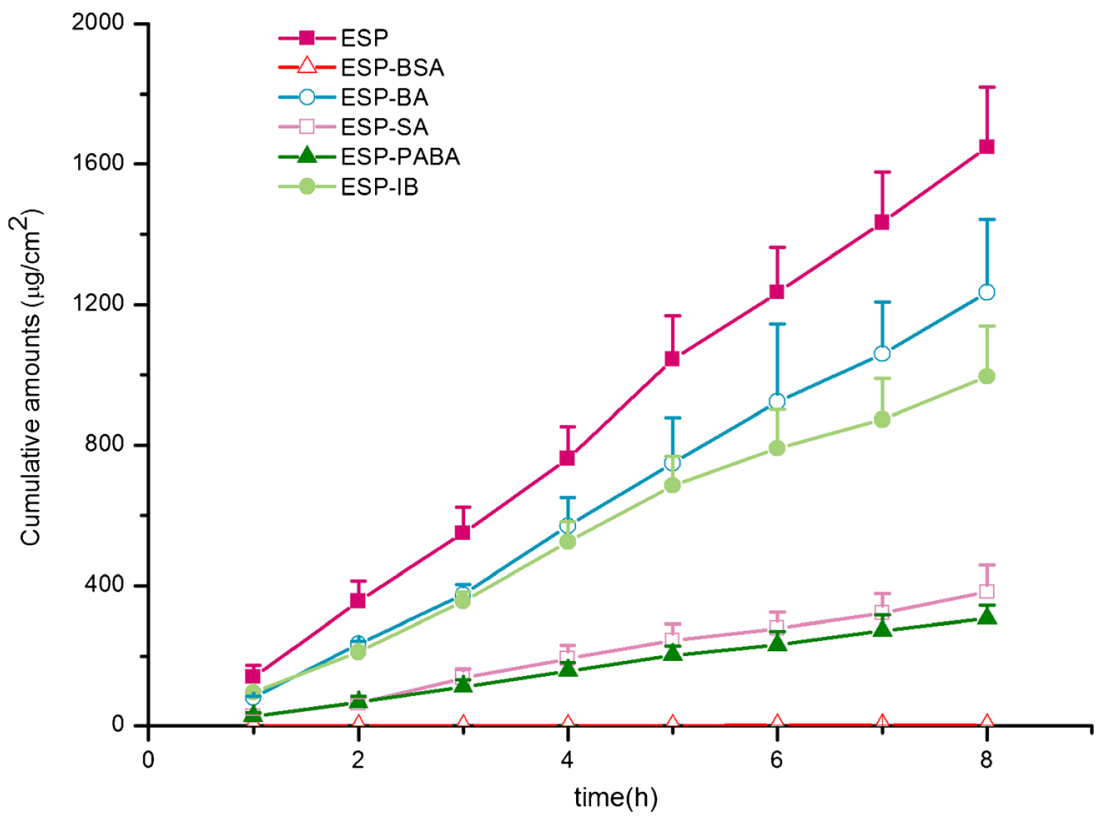

Fig. 4. Effect of organic acids on in vitro permeation of ESP across the rabbit skin (mean $\pm \mathrm{SD}, n=4$ )

and $M W$ can permeate through both SC and ED quickly. Considering the sustained skin permeation and the effective therapeutic plasma levels of ESP (19), five kinds of organic acids were used to format ion-pairs with ESP. According to the flux value of ion-pair complexes and their physicochemical properties listed in Table III, the skin permeability of ESP altered due to the altered physicochemical properties of ESP by forming ion-pair complexes with organic acids. Many previous studies about skin permeation reported that the physicochemical properties of drugs including $\log K_{\mathrm{o} / \mathrm{w}}$ and $M W$ could affect the skin permeability of drugs $(20,21)$. Ma et al. and Tan $e t$ al. also found that the flux of drug was influenced by the $\mathrm{p} K_{\mathrm{a}}$ of counter-ions $(22,23)$. The apparent solubility of ion-pair in the donor phases was also an important factor affecting the permeation rate (24). The controlled flux of ESP ion-pair complexes was also due to the low solubility in IPP. ESP-IB had a higher solubility but lower flux compared to ESP-BA, which suggested that there existed other factors affecting the flux.

Based on the multiple linear regression equation, the penetration ability of ESP ion-pair complexes declined mainly due to their decreased $\log K_{\mathrm{o} / \mathrm{w}}$. This was consistent with the previous studies about the correlation between the flux and $\log K_{\mathrm{o} / \mathrm{w}}(20,25,26)$. The flux of ESP significantly decreased after the ion-pair formation with SA and PABA, which

Table IV. Regression coefficients of the multiple linear regression equation

\begin{tabular}{lrrlrrr}
\hline Model & \multicolumn{2}{l}{$\begin{array}{l}\text { Unstandardized } \\
\text { coefficients }\end{array}$} & & $\begin{array}{l}\text { Standardized } \\
\text { coefficients }\end{array}$ & \multicolumn{1}{l}{$t$} & $P$ \\
\cline { 2 - 3 } & \multicolumn{1}{c}{$\mathrm{B}$} & Std. Error & & Beta & & \\
\hline Constant & 24.549 & 1.036 & & & \\
log $K_{\mathrm{o} / \mathrm{w}}$ & 3.154 & 0.118 & & 0.848 & 23.691 & 0.027 \\
$M W$ & -0.051 & 0.002 & & -0.665 & -23.808 & 0.024 \\
$\mathrm{p} K \mathrm{a}$ & 0.575 & 0.024 & & 0.506 & 24.073 & 0.027 \\
\hline
\end{tabular}

suggested that the hydrophilic hydroxyl and amino group in counter-ions might decrease the lipophilicity of ESP. IB had the biggest molecular size among the five organic acids, which made the ESP-IB complex had a higher $\log K_{\mathrm{o} / \mathrm{w}}$ but a relatively lower flux. The formation of ion-pairs increased the $M W$ of ESP and hindered its diffusivity, thus controlling the skin permeability. The acidity of organic acid was also an important factor affecting the permeability of ESP ion-pairs. Xi et al. had demonstrated that the larger $\mathrm{p} K_{\mathrm{a}}$ difference between the amine and acid, the more stable ion-pair complexes were and that led to a higher flux of Lornoxicam (18). Similarly, in our study, the stronger acidity of organic acids, the better control effect of ESP-acid complexes.

Our work provides new ideas for the application of ionpair complexes in regulating the skin permeation rate of drugs. And it's also the first time to use multiple linear regression model to comprehensively evaluate the effect of $\log K_{\mathrm{o} / \mathrm{w}}$, $M W$, and $\mathrm{p} K_{\mathrm{a}}$ on the flux of drugs, instead of discussing it

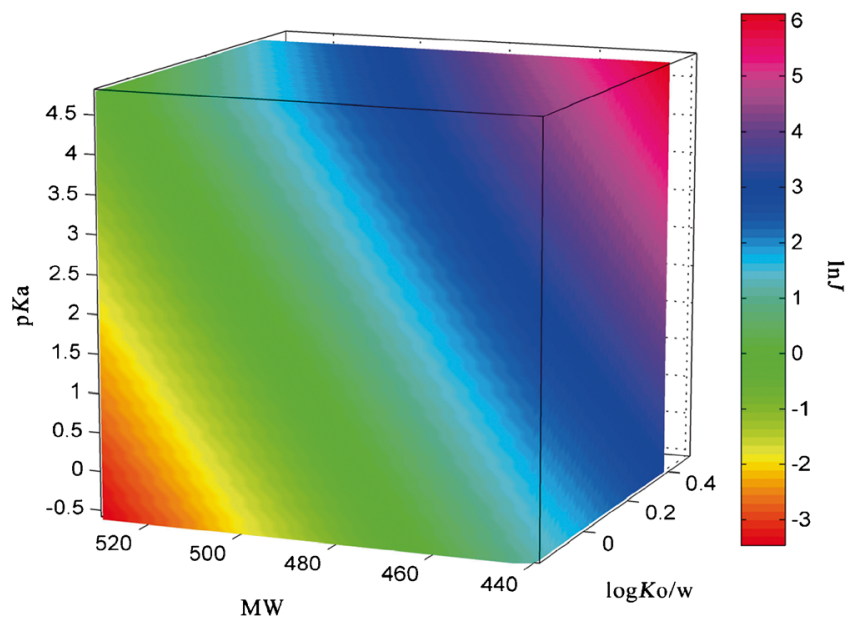

Fig. 5. Three-dimensional response surface plot illustrating the effect of $M W, \log K_{\mathrm{o} / \mathrm{w}}$ of ion-pair complexes, and the $\mathrm{p} K_{\mathrm{a}}$ of organic acid counter-ions on the flux of escitalopram 
individually. In further transdermal studies, we can choose different counter-ions with different physicochemical properties according to the requirement of skin permeation rate.

\section{CONCLUSION}

According to the results obtained in this work, ESP was promising to design into long-acting transdermal patches when forming ion-pair complexes with organic acids. Based on the multiple linear regression analysis, the physicochemical properties of ion-pair including $\log K_{\mathrm{o} / \mathrm{w}}, M W$, and $\mathrm{p} K_{\mathrm{a}}$ were the main factors influencing the transdermal permeability of ESP, and $\log K_{\mathrm{o} / \mathrm{w}}$ was the most influential one. Therefore, the ion-pair technology, a kind of simple and practical method, had a broad prospect in regulating skin permeation of drugs.

\section{REFERENCES}

1. Schosser A, Serretti A, Souery D, Mendlewicz J, Zohar J, Montgomery S, et al. European Group for the Study of Resistant Depression (GSRD) - where have we gone so far: review of clinical and genetic findings. Eur Neuropsychopharm. 2012;22(7):453-68.

2. Benatti C, Alboni S, Blom JM, Gandolfi F, Mendlewicz J, Brunello $\mathrm{N}$, et al. Behavioural and transcriptional effects of escitalopram in the chronic escape deficit model of depression. Behav Brain Res. 2014;272:121-30.

3. Malin P, Wengel SP, Burke WJ. Escitalopram: better treatment for depression is through the looking glass. Expert Rev Neurother. 2004;4(5):769-79.

4. Sultana J, Spina E, Trifirò G. Antidepressant use in the elderly: the role of pharmacodynamics and pharmacokinetics in drug safety. Expert Opin Drug Metab. 2015;11(6):883-92.

5. Kikuchi T, Suzuki T, Uchida H, Watanabe K, Mimura M. Association between antidepressant side effects and functional impairment in patients with major depressive disorders. Psychiatry Res. 2013;210(1):127-33.

6. Huang C-T, Tsai M-J, Lin Y-H, Fu Y-S, Huang Y-B, Tsai Y-H, et al. Effect of microemulsions on transdermal delivery of citalopram: optimization studies using mixture design and response surface methodology. Int $\mathrm{J}$ Nanomedicine. 2013;8:2295-304

7. Ivaturi VD, Kim SK. Enhanced permeation of methotrexate in vitro by ion pair formation with L-arginine. J Pharm Sci. 2009;98(10):3633-9.

8. Sarveiya V, Templeton JF, Benson HA. Effect of lipophilic counter-ions on membrane diffusion of benzydamine. Eur $\mathrm{J}$ Pharm Sci. 2005;26(1):39-46.

9. Song W, Cun D, Xi H, Fang L. The control of skinpermeating rate of bisoprolol by ion-pair strategy for longacting transdermal patches. AAPS Pharm Sci Technol. 2012;13(3):811-5.
10. Sun L, Cun D, Yuan B, Cui H, Xi H, Mu L, et al. Formulation and in vitro/in vivo correlation of a drug-in-adhesive transdermal patch containing azasetron. J Pharm Sci. 2012;101(12):4540-8.

11. Li C, Liu C, Liu J, Fang L. Correlation between rheological properties, in vitro release, and percutaneous permeation of tetrahydropalmatine. AAPS Pharm Sci Technol. 2011;12(3):1002-10.

12. Silverstein R, Webster F. Spectrometric identification of organic compounds. New York: John Wiley \& Sons; 2006. p. 236-47.

13. Arunan E, Desiraju GR, Klein RA, Sadlej J, Scheiner S, Alkorta I, et al. Defining the hydrogen bond: an account (IUPAC Technical Report). Pure Appl Chem. 2011;83(8):1619-36.

14. Korenaga T, Kobayashi F, Nomura K, Sakai T, Shimada K. The shielding effect of fluoroaromatic rings in NMR. J Fluorine Chem. 2013;156(12):1-4.

15. Tantishaiyakul V, Phadoongsombut N, Wongpuwarak W, Thungtiwachgul J, Faroongsarng D, Wiwattanawongsa K, et al. ATR-FTIR characterization of transport properties of benzoic acid ion-pairs in silicone membranes. Int J Pharm. 2004;283(1-2):111-6.

16. Ratajczak H, Sobczyk L. Dipole moments of hydrogen-bonded complexes and proton-transfer effect. J Chem Phys. 1969;50:556-7.

17. Hatanaka T, Kamon T, Morigaki S, Katayama K, Koizumi T. Ion pair skin transport of a zwitterionic drug, cephalexin. J Control Release. 2000;66(1):63-71.

18. Xi H, Wang Z, Chen Y, Li W, Sun L, Fang L. The relationship between hydrogen-bonded ion-pair stability and transdermal penetration of lornoxicam with organic amines. Eur J Pharm Sci. 2012;47(2):325-30.

19. Nilausen DØ, Zuiker R, van Gerven J. The perception and pharmacokinetics of a 20-mg dose of escitalopram orodispersible tablets in a relative bioavailability study in healthy men. Clin Ther. 2011;33(10):1492-502.

20. Cronin M, Dearden J, Moss G, Murray-Dickson G. Investigation of the mechanism of flux across human skin in vitro by quantitative structure-permeability relationships. Eur J Pharm Sci. 1999;7(4):325-30.

21. Magnusson BM, Anissimov YG, Cross SE, Roberts MS. Molecular size as the main determinant of solute maximum flux across the skin. J Invest Dermatol. 2004;122(4):993-9.

22. Tan Z, Zhang J, Wu J, Fang L, He Z. The enhancing effect of ionpairing on the skin permeation of glipizide. AAPS Pharm Sci Technol. 2009;10(3):967-76.

23. Ma X, Fang L, Guo J, Zhao N, He Z. Effect of counter-ions and penetration enhancers on the skin permeation of flurbiprofen. $\mathrm{J}$ Pharm Sci. 2010;99(4):1826-37.

24. Liu N, Song W, Song T, Fang L. Design and Evaluation of a Novel Felbinac Transdermal Patch: Combining Ion-Pair and Chemical Enhancer Strategy. AAPS Pharm Sci Tech. 2015

25. Moss GP, Cronin MTD. Quantitative structure-permeability relationships for percutaneous absorption: re-analysis of steroid data. Int J Pharm. 2002;238(1-2):105-9.

26. Frasch HF, Landsittel DP. Regarding the sources of data analyzed with quantitative structure-skin permeability relationship methods (commentary on 'Investigation of the mechanism of flux across human skin in vitro by quantitative structure-permeability relationships'). Eur J Pharm Sci. 2002;15(5):399-403.

27. Eikema HN, Clark T. Regression formulae for ab initio and density functional calculated chemical shifts. J Mol Model. 2005;11:175-85. 